\title{
Die ensiklopediese plek van Bybelkunde
}

\section{JJ Engelbrecht}

\begin{abstract}
The encyclopedic place of Biblical Studies

Is Biblical Studies part of theology, or has theology lost its grip on Biblical Studies, as it has lost its grip on Geology and Palaeontology as early as one and a half century ago?

Is it possible to distinguish between different levels of Biblical study, some levels dealing with essentially theological questions and others with more general questions of a historical, archaeological, literary or linguistic nature?

What is and should be the relationship between the Departments of Biblical Studies on the one hand, and the Departments of Old Testament and New Testament on the other hand?
\end{abstract}

\section{INLEIDING}

Hoewel die vak Bybelkunde reeds meer as twee dekades aan die Universiteit van Pretoria gedoseer word en Afdeling A van die Fakulteit Teologie van die begin af by die dosering van hierdie vak betrokke is, het die vraag na die ensiklopediese plek van Bybelkunde nou weer besonder aktueel geword: Tot dusver was die reëling dat die studente ingeskryf het by die Fakulteit Lettere en Wysbegeerte, maar dat die dosente aangestel is in die twee Afdelings van die Fakulteit Teologie, en dat die hoofde van die Departemente Ou- en Nuwe-Testamentiese Wetenskap (Afd A) en Ou- en Nuwe-Testamentiese Eksegese en Teologie (Afd B) ook die departementshoofde van die betrokke dosente in húlle afdeling van die Fakulteit was. Die Bybelkunde-dosentevergadering het gewoonlik die normale interne administratiewe sake gehanteer, terwyl beleidsake gehanteer is deur die Komitee vir Bybelkunde, bestaande uit die genoemde vier departementshoofde plus die voltydse dosente in Bybelkunde. 'n Paar jaar gelede het daar 'n verdere ontwik-

- Openbare voorlesing by die opening van die Fakulteit Teologie (Afdeling A), Universiteit van Pretoria, op 4 Februarie 1987. 
keling gekom in die sin dat die Nederduitse Gereformeerde Kerk (Ned Geref Kerk) se afdeling van die Fakulteit met 'n geïntegreerde kursus vir hul voornemende predikante begin het. Dit raak Bybelkunde in sover as wat voornemende Nederduitse Gereformeerde-predikante wat vroeër tydens hulle voorgraadse studie vir Bybelkunde ingeskryf het, nou nie meer vir Bybelkunde inskryf nie, maar wel, danksy 'n ooreenkoms met die Komitee vir Bybelkunde, sekere modules van hul teologiese kursus by Bybelkunde loop en oor daardie werk deur die Bybelkunde dosente geëvalueer word.

Hoewel alles nog nie in kanne en kruike is nie, kan vir alle praktiese doeleindes aanvaar word dat daar sedert 2 Januarie 1987 binne die Fakulteit Teologie 'n selfstandige Departement Bybelkunde tot stand gekom het, naas die bibliologiese departemente wat daar nog altyd was. Die een been van hierdie nuwe Departement staan in die fakulteitsafdeling van die Nederduitsch Hervormde Kerk van Afrika (NHKA) en die ander been in die afdeling van die Ned Geref Kerk, terwyl die departementshoofde om die beurt, soos die dekane van die Fakulteit, uit die twee fakulteitsafdelings sal kom. Die eerste departementshoof kom uit Afdeling B van die Fakulteit en sy dienstyd sal geld tot die einde van die dienstyd van die dekaan van die Fakulteit Teologie wat vanaf die einde van 1987 in diens tree - met dien verstande dat daardie dekaan nie lewenslank aaangestel is nie, maar soos in die verlede, vir 'n tydperk van drie jaar. Daarna word hy opgevolg deur iemand uit Afdeling A. Die situasie van die studente bly onveranderd.

Dit is byna vanselfsprekend dat die vraag na die ensiklopediese plek van Bybelkunde nou baie aktueel geword het en onder andere die volgende aspekte van die tema gaan nou kortliks aandag geniet, naamlik die vraag of die wetenskaplike bestudering van die Bybel nog tuishoort in die Fakulteit Teologie, en indien wel, wat die verhouding tussen Ou- en Nuwe-Testamentiese Wetenskap enersyds en Bybelkunde andersyds is. Die feit dat hierdie vrae aan die orde kom, impliseer natuurlik nie dat daar nie voorheen al daaroor nagedink is of dat klinkklare antwoorde reeds gegee kan word nie.

\section{BYBELKUNDE 'N WETENSKAP?}

Hoewel dit in hierdie kring seker as aksiomaties aanvaar word dat teologie 'n wetenskap is (vgl ook Van Huyssteen 1984; Eybers, König \& Stoop 1978; Heyns \& Jonker 1974; Roberts sa) en dat die Bybel wetenskaplik bestudeer kan en behoort te word, is dit miskien goed om 
daaraan herinner te word dat die sogenaamde Wienerkreis in die dertigerjare met 'n positivistiese wetenskapsbeskouing gekom het, waarmee hulle 'n natuurwetenskaplike wetenskapsbegrip die enigste norm vir wetenskaplikheid gemaak het. Later het wel geblyk dat hierdie positivistiese wetenskapsbeskouing waarvolgens langs die weg van induksie geredeneer is dat as water 99 keer by 100 grade $C$ gekook het, dit die volgende keer ook by daardie temperatuur sal kook, ook in die natuurwetenskap nie altyd werk nie. Dit het onder andere in die kernfisika geblyk dat in die wêreld van die fisika daar ook maar nie altyd so voorspelbaar gereageer word nie.

Later het Kühn gekom met sy teorie of hipotese dat ' $n$ mens altyd binne 'n bepaalde paradigma redeneer (vgl Van Huyssteen 1984). 'n Vooronderstellinglose wetenskapsbeoefening is nie moontlik nie (al het die Wienerkreis gedink dit is moontlik). In 'n bepaalde tydperk word gewerk binne 'n paradigma wat vir daardie tyd en situasie die geheime of raaisels kan help oplos deur bevredigende antwoorde te gee. Gaandeweg gebeur dit egter dat dit nie meer moontlik is om binne ' $n$ bepaalde paradigma bevredigende antwoorde te vind nie. Dan moet 'n nuwe paradigma ontwerp word. (Hierdie oorgang van een paradigma na ' $n$ ander vind [gewoonlik?] nie evolusionisties plaas nie, maar is [altyd] 'n skok [of die gevolg van 'n skok?].)

Onses insiens kan op grond van wat so pas gesê is, seker afgelei word dat nie alleen die beoefenaars van ' $n$ bepaalde natuurwetenskap enersyds en van 'n geesteswetenskap andersyds, binne verskillende paradigmas sal kan redeneer nie, maar dat ook teoloë van die een universiteit dalk ook binne 'n totaal ander paradigma as dië van 'n ander, teologie kan beoefen - en mekaar daarom dalk met die beste wil ter wëreld nie kan verstaan nie. Maar dit nou daar gelaat.

Dit was in ' $n$ artikel van James Barr, getitel 'Does biblical study still belong to theology?' (1980), dat ek vir die eerste keer met die verrassende en selfs skokkende vraag in die opskrif gekonfronteer is. Hy stel dat dit deesdae nie meer oral, soos in die verlede, die geval is dat die akademiese bestudering van die Bybel aan universiteite deel vorm van die kurrikulum van teologie nie. Anders as in die verlede is dit in sekere wêrelddele deesdae 'n bekende verskynsel dat al hoe meer mense die Bybel of die teologie bestudeer sonder dat hulle die minste begeerte het om as predikante georden te word. Baie wil ook nie eers voorgee dat hulle Christengelowiges is nie. Hulle volg hierdie studierigting bloot uit belangstelling, soos ' $n$ mens 'n taal of die filosofie of 
enige ander vak bestudeer. Dit geld ook van al hoe meer dosente in wat Barr 'Biblical Study' of 'Biblical Studies' noem (1980: 18).

In genoemde artikel betoog hy dat die teologie in die sin van 'n massa materiaal wat binne ' $n$ omvattende teologiese fakulteit bestudeer word, nie een enkele vak is in die sin wat Ekonomie of Wysbegeerte of Engels dit is nie. Dit is eerder ' $n$ konstellasie van verskillende studievelde en vakke wat bymekaargehou word deur die feit dat hulle bestudeer word soos wat hulle verband hou met God, met die kerk, die kerk se werk en tradisie en met die Bybel. Daar is dus nie een spesifieke teologiese metode of metodologie wat die hele veld dek nie. Elke teologiese vakgebied maak gebruik van metodes wat ontleen is aan nie-teologiese vakgebiede soos die Geskiedenis, die Literêre kritiek en die Wysbegeerte.

Genoemde faktore lei daartoe dat daar binne die teologie dikwels 'n groot toutrekkery plaasvind tussen die verskillende vakke. Tyd wat aan Hebreeus bestee word, lyk na tyd wat weggeneem is van Dogmatiek, en tyd wat aan Praktiese Teologie bestee word, lyk na tyd wat weggeneem is van Nuwe Testament. In die mate waarin teologie klem lê op hedendaagse probleme en die moderne filosofiese debat, word dit waarskynlik dat die sentrum van tegniese en gevorderde studie van die Bybel (Biblical Studies) weg van teologie sal beweeg. Vanweë die innerlike spanning kan die teologiese opleiding dalk self bydra tot die onafhanklikheid van die Bibliologiese studie (Biblical study) as akademiese studierigting (Barr 1980: 18-20). Nie-teologiese fakulteite en departemente soos klassieke tale, antieke geskiedenis, Semitiese tale, Joodse studies ensovoorts, lewer reeds 'n groot bydrae tot die verstaan van die Bybel.

Barr wys daarop dat ' $n$ mens sou kon dink dat dit hier gaan om die teenstelling tussen ' $n$ kerkgebonde teologiese fakulteit waarin eenstemmigheid sal bestaan dat Bybelkunde (Biblical Studies) deel vorm van teologie oor die algemeen, en daarteenoor 'n departement aan 'n sekulêre universiteit waar gewerk sou word met die gedagte dat dit niks met teologie te make het nie. In werklikheid is die saak egter veel meer kompleks. In sy land, Engeland, het Bybelkunde aan hul moderne universiteite dikwels skuiling gebied aan 'n tradisionele en konserwatiewe godsdienstigheid by die interpretasie van die Bybel, soos wat goedgekeur sou word deur 'n ouermodiese godsdienstige stroming, maar wat nie staande sou kon bly teen die skerp kritiese ingesteldheid van die moderne teologiese debat wat deeglik op hoogte is met die volle tradisie van die kerk se denke in moderne tye nie. Barr sê verder dat hy 
glad nie verbaas sal wees as hul ou universiteite met hul omvattende teologiese fakulteite in hul denke oor die Bybel 'n meer skeptiese gees huisves as die moderne sekulêre universiteite met hul minder teologiese benadering nie (Barr 1980: 21). Volgens Barr is die belangrikste aspek wat hier tersaaklik is, geleë in die denke van die Bybelkundige self: Hoe ver moet hy teologies dink en werk en hoe ver dink en werk hy werklik teologies?

\subsection{Wat is essensieel en spesifiek teologies?}

Om 'n antwoord te kry op die vraag wat essensieel en spesifiek as teologies bestempel kan word, antwoord Barr soos volg: 'n Mens kan miskien onderskei tussen twee elementêre logiese vorme. Die eerste is die vorm 'God is $X$ ', of 'Ons glo dat God X is', 'Ons behoort te bevestig dat God $X$ is.' Die tweede vorm is: 'Hierdie of daardie Bybelskrywer het gesê of gedink dat God $X$ is.' Eersgenoemde is 'n persoonlike geloofsuitspraak of ' $n$ weergawe van die kerk se geloof: dit is ' $n$ teologiese stelling in die enge sin. Die tweede vorm is ' $n$ deskriptiewe stelling: miskien histories, miskien struktureel, miskien hoort dit by ' $n$ ander kategorie, maar dit is 'n deskriptiewe stelling. Eersgenoemde stelling is nie bloot ' $n$ interpretasie van getuienis nie: die logika daarvan word nie volledig verklaar deur die getuienis te noem waarmee dit in verband staan nie. Die tweede stelling is ' $n$ interpretasie van gegewe getuienis.

Teologie in enge sin bring die gebruik van uitsprake in die eerste vorm mee: Dit is wat die kerk in sy belydenisse en in sy erediens sê, dit is wat die individuele gelowige sê, en dit is wat die teoloog sê. Maar'n groot deel van die akademiese studie van die Bybel neem skynbaar die tweede vorm aan: Dit sê nie wat God is nie, maar dit gee verslag oor wat die Bybeltekste oor Hom sê. Ons oorspronklike vraag, naamlik of wetenskaplike bestudering van die Bybel nog deel vorm van teologie, kan dus só herformuleer word: Moet die Bybelkundige ook van die eerste soort gevolgtrekkinge maak voordat hy op 'n genoegsame en omvattende wyse, waardeur die stof van die Bybel bevredigend gedek word, gevolgtrekkings van die tweede soort kan maak? Die kern van die vraag blyk dus te wees of die Bybelkundige in hierdie sin ' $n$ teoloog moet wees (Barr 1980: 22). (Hier word nie onderskei tussen Ou- en Nuwe-Testament enersyds en Bybelkunde andersyds nie.) Volgens Barr (1980: 23) lyk dit of die metodes van die Bybelwetenskappe 'n mengsel is van die metodes van die geskiedenis, die linguistiek, van literêre interpretasie en van die godsdienswetenskap (vlg Van der Merwe 1979), 
maar asof die teologie in die enger sin van die woord opsioneel is eerder as noodsaaklik. Die vraag kan gestel word of die teologie nie dalk sy kontrole oor die Bybelwetenskappe verloor het, soos hy dit reeds een en 'n halwe eeu gelede oor die Geologie en die Palaeontologie verloor het nie?

\subsection{Die eis van objektiwiteit}

Een van die maniere waarop 'n saak vir die onafhanklikheid van die Bybelwetenskappe dikwels gebou word, is deur die eis van objektiwiteit. Daar word gesê dat die studie van die Skrif op feitlike waarneming alleen gebaseer moet wees. Teologiese oortuigings sal dikwels die neiging hê om die feitlike gegewens te oordonder - vir dié van ons wat betrokke is by die Tussenkerklike Kommissie, is dit 'n oorbekende en onbehaaglike vermoede ten opsigte van sommige ander deelnemers, hoewel ons seker maar almal soms slagoffers van die gevaar word. Barr (1980: 23) sê dan ook tereg dat hierdie soort kritiek dikwels juis aansluit by uitsprake van teoloë wat sê dat iemand se teologiese oortuigings van so 'n aard is dat hy nie kan verstaan wat die Bybel werklik sê nie.

Hoewel dit waar is dat teologie objektiwiteit kan verwring en skade aandoen, kan sterk teologiese oortuiging saam bestaan met en hom verbly oor 'n hoë mate van objektiwiteit (Barr 1980: 24). Hoewel volkome objektiwiteit nie haalbaar is nie, is 'n hoë graad van objektiwiteit beslis verkieslik bo 'n lae graad van objektiwiteit. Daar bestaan talle voorbeelde van mense wat sterk teologiese oortuigings gehad het en toegewyde kerkmense was, wat op die terrein van byvoorbeeld die eksegese bekend was vir die groot erns waarmee hulle objektiewe en sobere hantering van die getuienis nagejaag het.

Die gedagte dat die uitsluiting van teologiese interesse sal lei tot objektiwiteit in die Bibliologiese studie, is dus nie aanvaarbaar nie. As die teologie uitgesluit word uit die akademiese studie van die Bybel, sal dit een van twee dinge tot gevolg hê: of sekere vrae sal glad nie gevra word nie, of 'n ander metafisiese veronderstelling sal die vakuum vul (Vgl ook Van Huyssteen 1984). Eersgenoemde gebeur vermoedelik meestal.

Op grond van sy ervaring meen Barr (1980: 25) dat sekere vlakke en dimensies van die Skrif glad nie ondersoek word nie, tensy geleerdes bereid is om, al is dit dan net vir die doeleindes van die argument, teologies te dink, te vra hoe dit sou wees as dit werklik waar sou wees van God. Hy ontleen 'n verdere voorbeeld uit 'n ander sfeer, naamlik 
die filosofie, as hy vra hoeveel armer die studie van die werk van 'n antieke denker soos Plato sou gewees het as geleerdes hulle deur die eeue heen net sou besig gehou het met die uitleg van die teks en sy interne semantiese skakels, terwyl hulle die vraag of Plato dalk gelyk het, rigoristies uit hul denke geweer het.

Tereg sê Barr (1980: 25-26) dat 'n mens egter te ver sou gaan deur die argument van persoonlike betrokkenheid oor te beklemtoon. Dit gebeur wanneer geredeneer word dat 'n studie van die Bybel slegs moontlik is wanneer die student empatie het met die stof in die sin dat hy self glo dat God hom deur middel van hierdie teks aanspreek. Volgens dié benadering moet die Bybel gelees word binne die konteks van die kerk en van die geloof van die kerk, wat op sy beurt op hierdie selfde Skrif gefundeer is.

Natuurlik word die studie van enige onderwerp verarm as empatie en betrokkenheid ontbreek; empatie en persoonlike betrokkenheid moet egter nie geïdentifiseer word met die aanvaarding van die teologiese of ideologiese posisie van die studiemateriaal nie. As die eis van empatie en persoonlike betrokkenheid te ver gevoer word, kan dit tot 'n onhoudbare solipsistiese posisie lei. Niemand sou dan 'n geldige mening oor 'n teologie of 'n filosofie kon uitspreek, tensy hy self 'n aanhanger is daarvan nie.

Die argument is egter wel geldig wanneer die studie van die Bybel as 'n teologiese taak onderneem word. Dan moet dit plaasvind binne die konteks van die kerk en met 'n persoonlike betrokkenheid wat verband hou met daardie konteks. Dit bewys egter nie dat geldige studie van die Bybel slegs binne daardie konteks moontlik is nie.

\subsection{Die plek van vooronderstellings}

'n Ander argument wat soms te ver gevoer word, is die van die onvermydelikheid van vooronderstellings (Barr 1980: 26-9). Vanuit die premisse dat geen vooronderstellinglose wetenskapsbeoefening moontlik is nie, word soms die groot sprong gemaak om te sê dat die teologie die dissipline is wat die vooronderstellings van die Bybelstudent kan ondersoek en kritiseer. Ander meen selfs dat die teologie aan die navorser die korrekte vooronderstellings kan gee. Daar word geïmpliseer dat die Bybelwetenskaplike teologiese of kwasie-teologiese vooronderstellings het, maar dat hy dit vir homself en vir ander kan wegsteek. 'n Uitdruklike verband met die teologie veroorsaak dat hierdie vooronderstellings aan die lig kom en dat Bybelnavorsing op die een of ander manier beter op sy objek gerig word. 
Hoewel dit waar is dat Bybelwetenskaplikes geneig is om die onderliggende vooronderstellinge van hul arbeid te verswyg, toon hierdie argument nie aan dat (a) hulle werk beter of meer diensbaar vir die teologie sou wees as hulle vooronderstellings deegliker bespreek was nie en (b) dat die teologie as sodanig beter in staat is om hierdie vooronderstellings bloot te lê, te bespreek of geldig te maak nie.

Laat ons toegee dat die blootlegging van vooronderstellings heilsaam en stimulerend kan wees. Hieruit kan egter nie afgelei word dat die struktuur van die studie van die Bybel positief gebou kan word op die fondament van 'n vooronderstelling of vooronderstellings nie (Barr 1980: 27). Kritiek op vooronderstellings kan ons help om te verstaan hoe en waarom sekere verkeerde draaie in die betrokke dissipline gemaak is; dit sê egter nie vir ons hoe om die regte draaie te maak nie. Die regte vooronderstellings verskaf geen metodes nie en waarmerk geen gevolgtrekkings nie. Die beskouing van 'n Bybelkundige staan of val nie by die verband tussen sy beskouing en sy vooronderstellings nie, maar by die verband tussen sy opvatting en die beskikbare getuienis (Barr 1980: 28).

Anders gestel: Dit is in die belang van die teologie dat dit die Skrif sal toelaat en aanmoedig om vryelik tot die kerk en die teologie te spreek. Dit moet in staat wees om iets anders te sê as wat die heersende teologiese en uitleggebruike sou verwag dat dit moet sê. Dit is egter onmoontlik as die teologie die vooronderstellings kontroleer waarmee hierdie studie verrig moet word. Dit is dus in belang van die teologie dat hierdie dissipline 'n bepaalde onafhanklikheid moet hê (vgl ook Van Huyssteen 1974: 4;1984: 11-12; Roberts s a: 49-50).

Hiermee is dus die onhoudbaarheid van twee ekstreme standpunte seker aangetoon: Die een standpunt dat objektiwiteit verkry moet word deur die uitsluiting van teologiese oorwegings by die studie van die Bybel, en die ander standpunt dat die Bybel hoegenaamd nie verstaan kan word behalwe op teologiese wyse nie.

Die korrekte benadering is waarskynlik, aldus Barr (1980: 28), om te erken dat die studie van die Skrif ' $n$ baie komplekse aangeleentheid is wat op baie verskillende vlakke en op baie verskillende wyses beoefen word. Sommige vlakke, kom ons noem dit, sonder om neerhalend te wees, die 'laer vlakke', kan bestudeer word sonder om enigsins teologiese beslissings te vel. Daar is egter ander vlakke, noem dit die 'hoër vlakke', waar meer teologiese vrae, indien nie onvermydelik nie, in elk geval natuurlik is. Dog die geldigheid van 'n gevolgtrekking op hierdie vlakke berus nooit net op teologiese oorwegings nie, maar ook op die 
data wat ontleen is aan die laer vlakke waar dit aan nie-teologiese kontrole onderworpe is.

Bybelkunde (in die wyer sin waarin Barr dit gebruik) bestaan dus as 'n herkenbare dissipline; dit is nie noodwendig apart van teologie nie en dit is ook nie noodwendig geïntegreer met teologie nie. As dit van teologie geskei is, kan dit sekere dinge nie behoorlik doen nie, is dit armer en is teologie ook armer. Die verlies kan egter nie voorkom word deur daarop aan te dring dat Bybelkunde slegs teologies kan wees nie. Teologiese studie van die Bybel vind plaas binne die konteks van die kerk, maar ook binne die konteks van 'n wyer akademiese gemeenskap. Dit kan die konteks van die kerk slegs na behore dien in so ver as wat dit erns maak met die studiemetodes en interpretasiemetodes wat in daardie wyer gemeenskap geld en waaroor die teologie as sodanig geen uitspraak kan gee nie. (Barr 1980: 29; vgl ook Van Huyssteen 1984: 9-17).

\section{BYBELKUNDE IN VERHOUDING TOT OU- EN NUWE- TESTAMENTIESE WETENSKAP}

In hierdie voordrag het ons tot dusver nog nie skerp onderskei tussen Ou- en Nuwe-Testamentiese Wetenskap enersyds en Bybelkunde andersyds nie. Op voorgraadse vlak lyk dit redelik maklik om te onderskei, deur te sê dat dit 'n soort elementêre inleiding is tot genoemde teologiese vlakke - elementêr in die sin dat geen kennis van die oorspronklike Bybeltale verwag word nie en dit vir die meeste studente hul eerste kennismaking met 'n wetenskaplike bestudering van die Bybel is. Verder is Bybelkunde, soos dit aan die Universiteit van Pretoria en ander inrigtings hier te lande beoefen word, nie primêr gerig op die opleiding van voornemende teoloë nie. Veral op tweedeen derdejaarsvlak is die meeste studente voornemende onderwysers, terwyl ' $n$ hele aantal die vak bloot uit belangstelling bestudeer. Die vak het dus in sekere opsigte ' $n$ ander gerigtheid en funksie as Ou- en Nuwe-Testamentiese Wetenskap wat aangebied word vir voornemende teoloë en teoloë in die Fakulteit Teologie.

Op nagraadse vlak is die onderskeid om verskeie redes nie so duidelik nie. Daar kan byvoorbeeld genoem word dat vir die honneursstudie Hebreeus 110 en 120 asook Grieks 110 en 120 vereis word. Vir die M A-graad word 'n tweedejaarsvlak in Hebreeus of Grieks verwag, terwyl aan die doktorale studente ook hoër taalvereistes gestel kan word. 
Dit is ' $n$ vaste beleid dat ' $n$ nagraadse kwalifikasie in Bybelkunde nie 'n laer akademiese standaard mag hê as 'n vergelykbare graad met $\mathrm{Ou}$ of Nuwe Testament as hoofvak nie. Hieruit vloei onmiddellik 'n paar belangrike vrae voort:

- Watter stof moet by Bybelkunde addisioneel aangebied word om te kompenseer vir die feit dat die studente nie een van die ander teologiese vakke neem nie?

- Kan daar 'n grenslyn getrek word tussen stof waaroor 'n nagraadse student in Bybelkunde 'n verhandeling of 'n proefskrif mag skryf en dié waaroor 'n teologiese student in die betrokke departemente mag skryf? Indien wel, watter norme geld vir hierdie afbakening?

(Terloops wys ons daarop dat die grade van Bybelkundestudente in die Fakulteit Lettere en Wysbegeerte toegeken word.)

Oor die teologie as wetenskap en oor die verhouding van Bybelkunde tot teologie en tot $\mathrm{Ou}$ en Nuwe Testament, het op die Afrikaanse taalgebied reeds belangrike publikasies verskyn, al is dit nie omvangryk nie. Die leser is reeds verwys na Eybers (1978), Heyns en Jonker (1974), König (1978), Lombard (1973) en Roberts (s a), terwyl PJ van der Merwe (1979) hom besig hou met die verwante vraag na die plek van die godsdienswetenskap - by Lettere en Wysbegeerte of by Teologie? Alle verskille in benadering en aanpak ten spyt, bestaan by geeneen van genoemde outeurs, vir sover as wat hulle hul daaroor uitlaat, twyfel oor die belangrikheid van Bybelkunde as wetenskap en oor die feit dat dit baie sinvol vanuit die Fakulteit Teologie aangebied kan word nie.

Op die vraag of dit wetenskaplik verantwoordbaar is dat Bybelkunde gedoseer kan word en dat daar selfs 'n Departement Bybelkunde kan bestaan sonder dat op alle genoemde belangrike vrae reeds klinkklare antwoorde gegee kan word, kan in alle beskeidenheid só geantwoord word: Daar was mense wat, eeue voordat die Bybel tot stand gekom het, in God geglo het; die nadenke en prediking oor die boodskap van die Bybel was al vir baie eeue aan die gang voordat die teologiese wetenskap tot stand gekom het; die teologie is beoefen voordat die dissipline 'Ensiklopedie van die teologie' beoefen is. Bybelkunde is 'n werklikheid, selfs al is daar nog baie onbeantwoorde vrae oor sy ensiklopediese plek en al beleef die dissipline van die ensiklopedie die vak miskien nog as 'n Fremdkörper in die Fakulteit Teologie!

Wat die toekoms betref kan dit dalk sinvol wees om weer 'n keer deeglik aandag te skenk aan die vraag of Bybelkunde nie ook vir die opleiding van voornemende predikante in die NHKA se deel van die 
Fakulteit Teologie beter benut kan word nie. Sou die B D-student byvoorbeeld nie op 'n hoër vlak met sy B D-studie in die Bybelwetenskappe kon begin as alle $B$ D-studente tydens die voorstudie reeds tot op 'n tweede- of derdejaarsvlak met Bybelkunde gevorder het nie?

Hoewel die verspreiding van een departement oor die twee afdelings van die Fakulteit Teologie soms organisatoriese en ander probleme meebring, het dit dalk in ander opsigte belangrike voordele: Vir albei die betrokke kerke bring dit 'n besparing aan mannekrag en ook op finansiële gebied mee. Die wisselwerking tussen vakmanne uit die betrokke twee kerke is nie te versmaai nie en die studente ervaar dat dit moontlik is om oor eie kerklike grense heen, sinvol besig te wees met die bestudering van die Bybel. Vir die ekumeniese kontak in die goeie sin van die woord, kan dit dalk baie waardevol wees.

\section{GEVOLGTREKKING}

Hoewel die NHKA en die Ned Geref Kerk in baie opsigte geïsoleerd staan in die kerklike wêreld, kan daar blykbaar tog op kerklike en wetenskaplike gronde 'n sterk saak voor uitgemaak word dat sowel Ouen Nuwe-Testamentiese Wetenskap as Bybelkunde deur departemente binne die Fakulteit Teologie aangebied word.

Ek dink ons in ons Kerk kan onsself gelukkig ag dat dit moontlik is om nie alleen $\mathrm{Ou}$ - en Nuwe-Testamentiese Wetenskap nie, maar ook Bybelkunde, binne en vanuit die Fakulteit Teologie te kan aanbied, danksy die ooreenkoms met die Universiteit van Pretoria. Hoewel minstens Bybelkunde ook in ' $n$ ander fakulteit aangebied sou kon word, is dit ook goed moontlik om dit op 'n wetenskaplik verantwoorde wyse by teologie aan te bied. Dit is vir die Kerk egter ook nog 'n voorreg, omdat dit vir die Kerk sekerlik belangrik is dat die studente wat die Bybel wetenskaplik moet leer bestudeer, sal weet en sien dat die dosente wat hierdie boek, wat vir die Kerk die allerbelangrikste boek is, wetenskaplik probeer bestudeer, dit nie doen omdat hulle ontken dat dit 'n Godgegewe boek is nie, maar juis omdat hulle alle beskikbare middele wil gebruik om so ver as moontlik seker te maak dat hulle én hulle studente, die BOODSKAP van hierdie boek reg sal verstaan!

\section{Literatuurverwysings}

BARR, J 1980. Does Biblical study still belong to theology?, in Explorations in theology, 7:

The scope and authority of the Bible, 18-29. London: SCM. 
EYBERS, IH 1978. Bybelkunde, in Eybers, IH, König, A \& Stoop, JA (reds), Inleiding in die teologie, 37-44. 2de hersiene en uitgebreide uitgawe. Pretoria: NG Kerkboekhandel.

HEYNS, JA \& JONKER, WD 1974. Op weg met die teologie. Pretoria: NG Kerkboekhandel.

KONIG, A 1978. Teologie, in Eybers, IH, König, A \& Stoop, JA (reds). Inleiding in die teologie, 1-36. Pretoria: NG Kerkboekhandel.

LOMBARD, JC 1973. Die betekenis van Bybelkunde as akademiese dissipline: Intreerede. s I: UOVS.

ROBERTS, JH s a a. Die studie van Bybelkunde as teologiese vak, in Roberts, JH \& Du Toit, AB, Inleiding tot die studie van die NT: kanoniek van die NT, 49-50. Pretoria: NG Kerkboekhandel. (Handleiding by die NT 1V.)

ROBERTS, JH s a b. Inleiding tot die studie van die NT: Prinsipiële gesigspunte en terreinverkenning, in Roberts, JH \& Du Toit, AB, Inleiding tot die studie van die NT: Kanoniek van die NT, 3-84. Pretoria: NG Kerkboekhandel (Handleiding by die NT 1V.)

VAN DER MERWE, PJ 1979. Die godsdiens as probleem vir die wetenskap en die teologie. Pretoria: UP. (Publikasies van die Universiteit van Pretoria. Nuwe reeks. Intreerede.)

VAN HUYSSTEEN, JWV 1974. Wat is Bybelkunde? Intreerede. Port Elizabeth: Universiteit van Port Elizabeth.

VAN HUYSSTEEN, JWV 1984. Bybelkunde op universiteit as 'n vormende wetenskap. Scriptura $13,8-20$. 